\title{
REVIEW
}

\section{Molecular regulatory mechanism of tooth root development}

\author{
Xiao-Feng Huang ${ }^{1}$ and Yang Chai ${ }^{2}$ \\ The root is crucial for the physiological function of the tooth, and a healthy root allows an artificial crown to function as required \\ clinically. Tooth crown development has been studied intensively during the last few decades, but root development remains not well \\ understood. Here we review the root development processes, including cell fate determination, induction of odontoblast and \\ cementoblast differentiation, interaction of root epithelium and mesenchyme, and other molecular mechanisms. This review \\ summarizes our current understanding of the signaling cascades and mechanisms involved in root development. It also sets the stage \\ for de novo tooth regeneration. \\ International Journal of Oral Science (2012) 4, 177-181; doi:10.1038/ijos.2012.61; published online 7 December 2012
}

Keywords: Hertwig's epithelial root sheath; periodontium; root development; tooth development

\section{INTRODUCTION}

Human diseases of the tooth root have been long recognized. In 1944, Brown first reported one case of hypoplasia of the tooth root. ${ }^{1}$ In 1972 , Lind introduced the concept of short root anomaly disease. ${ }^{2}$ The etiology of tooth root hypoplasia or short root anomaly disease is complicated and includes autosomal dominant inherited diseases (SingletonMertern syndrome, Ehlers-Danlos syndrome, etc.), Osteopetrosis (CLCN7 mutations) and hypophosphatasis. ${ }^{3-5}$ The developmental processes of root formation are affected in these diseases.

The tooth is one of the best models for developmental biology and organ regeneration studies. The process of tooth development, the critical molecules involved in tooth crown formation and its reciprocal induction events have been addressed by multiple studies in recent years. $^{6-12}$ In mammals, the root is an important part of the whole tooth. Root development follows crown formation. Research on root development has made great progress in recent years. ${ }^{13-21} \mathrm{~A}$ biological root has also been regenerated and functions in animal studies. ${ }^{22-25}$

Here, we review the tooth root development literature and describe the dental epithelial and mensenchymal contributions to root development with a detailed morphological and molecular analysis. This review will highlight the research on root development in recent years and will promote the understanding of processes required for tooth regeneration in the future.

\section{PROCESSES OF ROOT DEVELOPMENT}

Tooth development is a complex physiological process that includes the bud, cap and bell stages, tooth root development and tooth eruption. ${ }^{6-12}$
The interaction between dental epithelial and neural crest derivedmesenchymal cells is essential for tooth development. ${ }^{7,26}$ After the crown formation is nearly complete, the tooth root begins to develop with the guidance of the double layer of the epithelial sheath, called the Hertwig's epithelial root sheath (HERS). The HERS is formed from the outer and inner enamel epithelium at the neck ring of the crown and grows in the apical direction. Morphologically, the epithelial root sheath is located between the two regions of neural crest-derived mesenchyme: the dental papilla and the dental follicle. When the HERS grows apically, the dental papilla cells adjacent to the inner epithelial layer of the HERS and the epithelial basement membrane are induced to become odontoblasts, and later to form root dentin. After root dentin formation, the epithelial root sheath enveloping the root begins to be interrupted or perforated. The formation of a mesh-like structure in the HERS allows dental follicle cells to contact the newly formed root dentin surface through the epithelial root sheath. These dental follicle cells differentiate into cementoblasts to form cementum. In addition, some of the HERS cells undergo epithelialto-mesenchymal transition to become cementoblasts and form cementum. At the same time, collagen fibers secreted by dental follicle cells are embedded into the new cementum matrix and fix the root in the jaw bone. Following tooth root development and elongation, the tooth erupts into the oral cavity to establish occlusal contacts with opposing teeth and performs its physiological function. ${ }^{19,21,27-28}$

\section{CELL DIFFERENTIATION OF THE TOOTH ROOT}

During tooth root development, all functional hard tissues are formed by three kinds of cells: HERS, dental papilla mesenchymal and dental

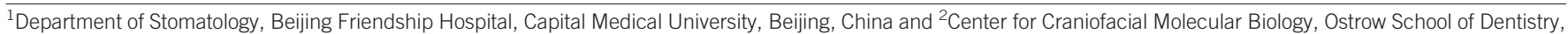
University of Southern California, Los Angeles, USA

Correspondence: Dr Y Chai, Center for Craniofacial Molecular Biology (CCMB), Ostrow School of Dentistry, University of Southern California, 2250 Alcazar St. CSA 103, Los

Angeles CA 90033, USA

E-mail: ychai@usc.edu

Or Dr XF Huang, Department of Stomatology, Beijing Friendship Hospital, Capital Medical University, Beijing 100050, China

E-mail: hxf1998@hortmail.com

Received 4 November 2012; accepted 8 November 2012 
follicle cells, which form developing apical complexes. ${ }^{19,21,29}$ Developing apical complexes are located in the apical region of the developing tooth and can develop an entire tooth root in vitro, independently without a crown. The hard tissues in the root, dentin and cementum, are formed by odontoblasts and cementoblasts, ${ }^{30-31}$ which are derived from the dental mesenchyme.

\section{Dentin formation}

Dentin is a pale yellow substance that is the major component of the tooth hard structure covering the dental pulp. At the beginning of root development, the two layers of the HERS form before the appearance of root dentin. The basement membrane of the HERS is secreted by both dental epithelial and mesenchymal cells and acts as an inducer for odontoblast differentiation. Laminin 5 is secreted by the HERS and can induce dental papilla cell attachment, growth, migration and differentiation. ${ }^{32}$ The HERS also secretes transforming growth factor-beta (TGF- $\beta$ ), which induces the differentiation of dental papilla cells into odontoblasts. ${ }^{33-36}$ If the continuity of the HERS is disrupted, the dental papilla cells fail to differentiate. Thus, the HERS is critical for root dentin formation.

Although the structure and composition of dentin in the crown and the root are similar, their development varies. Morphologically, mature odontoblasts in the crown are elongated and stylolitic, but they are cubic in the root region. At the molecular level, nuclear factor Ic (Nfic) appears to play an important role in root, but not crown, dentin formation. If Nfic is knocked out in the dental mesenchyme, dentin fails to form, but instead bone-like mineral material is detectable, with odontoblasts that are not polarized or embedded in the cellular dentin. In contrast, odontoblasts in the crown pulp differentiate and dentin develops in Nfic mutant mice. ${ }^{17-18,20,37}$ Therefore, the mechanism of dentin formation in the crown and the root must be different.

\section{Cementum formation}

The mature mammalian tooth root is covered by cementum on its surface and is stabilized by periodontal ligament fibers, which are embedded in both the cementum and alveolar bone. The cementum contains acellular and cellular cementum. In most of the teeth, cellular cementum covers the apical one-third of the root, and acellular cementum covers the rest. Cellular intrinsic fiber cementum appears after injury of the root and is called repaired cementum. Cellular cementum is a bone-like mineralized tissue attached on the surface of root dentin or, in some animals, crown enamel. Cementum formation begins when both epithelial cells of the HERS and mesenchymal cells of the dental follicle are in proximity to the developing root surface. The relative contribution of epithelial and mesenchymal components to cementogenesis remains an area of debate. Previous studies have suggested that cementum is a dental follicle-derived connective tissue that forms subsequent to HERS disintegration. In 2009, we reported that HERS cells on the surface of the root can also express cementoblast markers, such as collagen I and bone sialoprotein. In the root apical region, HERS cells are embedded in the cellular cementum and express ALPase. Some of the HERS cells on the surface of the acellular cementum also express ALPase. Our results are consistent with epithelial-mesenchymal transformation during root development, which was suggested by several previous studies showing that dental follicle as well as dental epithelial cells participates in cementogenesis. ${ }^{14,19,38-42}$

\section{Periodontal ligament formation}

Periodontal ligaments are derived from the dental follicle. The initiation of dental ligament formation begins at the stage when HERS interruption is detectable. After interacting with the HERS, pro-fibroblasts migrate to the root surface and alveolar bone surface. The tiny and short collagen fibers attach to the root surface and grow into the periodontal space. The fibers embedded in the cementum are called Sharpey's fibers. The arrangement of these fibers at the early root developmental stage is disordered. Later, the fibroblasts, pre-fibroblasts and stem cells in the dental follicle are activated and the fibers grow thick and well-organized. These strong fibers are important for linking the root and alveolar bone and to stabilize the tooth in the alveolar bone securely for the function of mastication. ${ }^{14,31,43}$

\section{INTERACTION BETWEEN THE EPITHELIUM AND MESENCHYME DURING ROOT DEVELOPMENT}

The interaction between the epithelium and mesenchyme plays an essential role in ectodermal organogenesis, such as that in the lung, kidney, glands and hair. ${ }^{44-48}$ During tooth root development, the epithelium is located between the neural crest-derived mesenchyme tissues, the dental papilla and dental follicle. The sandwich-like arrangement of the developing root apical structure suggests that there is interaction between the dental epithelium and mesenchyme during root formation.

\section{Function of the dental epithelia during root development}

The dental epithelium in the root is different from that of the crown. Unlike epithelial cells in the crown, HERS cells do not respond to certain signals from the dental mesenchyme and do not differentiate into ameloblasts. The function of the HERS is not the same as the crown epithelium either. The HERS functions as an inducer of odontoblast and cementoblast differentiation, root growth and division of dental apical foramen, and it may help to determine root number. Some of the epithelial root sheath cells directly differentiate into cementoblasts or cementocytes during root development. ${ }^{21}$

If the continuity of the epithelial root sheath is interrupted too early during root dentin formation, odontoblast differentiation will be affected and the dental pulp and periodontal ligament will connect together without dentin in the affected region, where the collateral root canals are present. In contrast, if the epithelial root sheath fails to become interrupted at the correct developmental stage (postnatal day 7 or later in mice) and remains attached to the surface of the root, the dental follicle mesenchymal cells cannot penetrate the HERS to contact the dentin and cannot be induced to become cementoblasts to form cementum. Then, the root dentin surface, in particular the cervical region of the tooth, is exposed, causing tooth sensitivity. ${ }^{49}$ Therefore, the HERS is essential for the formation of both dentin and cementum during root development and may be considered the developmental center for root formation.

HERS also plays an essential role in determining root number. At approximately postnatal day 12 , the buccal and lingual processes of the first mouse molar - the multiroot tooth-grow horizontally and contact each other to form the furcation of the tooth and give rise to the root contour. After segregation into multiroot canals, each root continues its elongation to complete root formation. ${ }^{21,50}$

\section{Fate of the HERS}

Previously, the fate of HERS cells was evaluated by continuous histological observations. Recently, we traced HERS cells using the Creloxp system (Keratin-14 (K14)-Cre; R26R-transgenic mice) and found that HERS cells are detectable on the surface of the root throughout root formation and do not disappear. Most of the HERS cells are attached to the surface of the cementum and others separate to become the epithelial rest of Malassez. HERS cells secrete extracellular matrix 
components onto the surface of the dentin before dental follicle cells penetrate the HERS network to contact dentin. HERS cells also participate in cementum development and may differentiate into cementocytes. Therefore, based on our findings and that of others, at least six possible outcomes for HERS cells have been proposed: (i) becoming the epithelial rest of Malassez; (ii) apoptosis; (iii) incorporation into the advancing cementum front; (iv) epithelial-mesenchymal transformation; (v) migration toward the periodontal ligament; and (vi) differentiation into cementoblasts. ${ }^{15,51-57}$

\section{Function of the dental mesenchyme during root development}

The role of the dental mesenchyme in HERS induction during root development is not so clear. The primary hard tissue of root dentin is formed by odontoblasts, which have differentiated from dental papilla cells. Cementum is mostly formed by cementoblasts, which have differentiated from dental follicle cells. Molecules such as TGF- $\beta$, Nfic, insulin-like growth factors, WNTs and fibroblast growth factors (FGFs) contribute to odontoblast and cementoblast terminal differentiation. ${ }^{16,58-63}$ Bone morphogenetic proteins (BMPs) and Fgf signaling in the dental mesenchyme may participate in the induction of the HERS, because Bmp3, Bmp4 and Fgf10 are expressed strongly before root development. The number of roots and direction of root formation may also be influenced by the mesenchyme and structures derived from the mesenchyme.

\section{MOLECULAR MECHANISMS OF ROOT DEVELOPMENT}

\section{Gene expression during root development}

Various genes, including TGF- $\beta$, BMPs, FGFs, Sonic hedgehog (Shh), Notch, Gli, Msx1, Msx2, Nfic and others, are involved in the process of root development. ${ }^{16,58-63}$ We list the expression of various genes in different structures of the developing tooth root, including the dental epithelium (HERS), dental papilla and dental follicle (Table 1).

\section{Tgf- $\beta /$ Bmp signaling}

The TGF- $\beta$ superfamily of cytokines is comprised of TGF- $\beta$ s, BMPs, activins and related proteins. TGF- $\beta$ signaling plays an important role in developmental biology, disease, and regeneration. ${ }^{64-66}$ The canonical TGF- $\beta$ signaling pathway involves the TGF- $\beta$ ligand binding to the type II and type I receptors. The activated receptor complex phosphorylates Smad proteins (R-Smads), which form a complex with the common Smad (Smad4). The Smad complex then translocates into the nucleus to regulate the expression of an array of target genes. ${ }^{67-69}$ Tgf- $\beta$ signaling is important for cementum formation. In cellular cementum, Tgf- $\beta$ is strongly expressed in cementoblasts. Tgf- $\beta$ also induces the expression of Timp, inhibiting metal proteinases and inducing periodontal ligment cell proliferation and synthesis of extracellular matrix.

Tgf- $\beta$ signaling in both the dental epithelium and mesenchyme also plays essential roles in root dentin formation and root development. ${ }^{20,36,70}$

Smad4 is a central mediator of the canonical TGF- $\beta$ signaling pathway. Deletion of Smad4 results in blockage of TGF- $\beta /$ Bmp signaling. Ablation of Smad4 in the dental mesenchyme (Osr2-IresCre;Smad4 $4^{f / f l}$ mice) results in short root formation and defects in odontoblast differentiation and dentin formation. Moreover, ectopic bone-like structures replaced normal dentin in the teeth of Osr2-IresCre;Smad4 $4^{f l f l}$ mutant mice. Loss of Smad4 results in upregulation of canonical WNT signaling, and downregulation of Dkk1 and Sfrpl, which are WNT pathway inhibitors. ${ }^{70}$ Comparing different animal models provides more detail about Tgf- $\beta$ signaling during root dentin forma-
Table 1 Gene expression during root development

\begin{tabular}{|c|c|c|c|c|}
\hline Items & $\begin{array}{c}\text { Dental } \\
\text { epithelium }\end{array}$ & Dental papilla & Dental follicle & Cementoblast \\
\hline Tgf-beta1 & + & & & \\
\hline Bmp2 & + & + & $+^{*}$ & \\
\hline Bmp3 & & + & & + \\
\hline Bmp4 & + & + & & \\
\hline Bmp7 & + & + & & + \\
\hline Egf & & & $+^{*}$ & \\
\hline Egfr & + & & & \\
\hline Fgf1 & + & & & \\
\hline Fgf2 & + & & & \\
\hline Fgfr1 & + & & & \\
\hline Fgfr2 & + & & & \\
\hline Notch1 & + & & & \\
\hline Notch2 & + & & & \\
\hline Notch3 & + & & & \\
\hline Shh & + & & & \\
\hline Ctgf & + & & $+*$ & \\
\hline Timp1 & & + & & \\
\hline Timp2 & + & & & \\
\hline Timp3 & + & & & \\
\hline IGF & + & & & \\
\hline HGF & + & & & \\
\hline Msx1 & & + & & \\
\hline Msx2 & + & + & + & + \\
\hline Runx2 & & + & $+^{*}$ & \\
\hline Nfic & & + & & \\
\hline Smad4 & + & + & + & + \\
\hline
\end{tabular}

BMP, bone morphogenetic protein; FGF, fibroblast growth factor; HGF, hepatocyte growth factor; IGF, insulin-like growth factor; Nfic, nuclear factor Ic; Shh, Sonic hedgehog. * Our unpublished data.

tion. In Osr2-IresCre;Smad4 $4^{f l / f l}$ mice, dental mesenchyme differentiation is arrested at the late bell stage and secretory stage, with no detectable expression of Dspp. Odontoblast differentiation is delayed and Dspp expression is eventually detectable in mice lacking Tgfbr2 $\left(W n t 1-C r e ; T g f b r 2^{f l / f l}\right){ }^{36}$ In contrast, odontoblast cell polarization is not affected in newborn Osr2-IresCre;Bmpr1 $a^{f l f l}$ mice, in which BMP signaling is blocked in the dental mesenchyme. These results demonstrate that Tgf- $\beta$, but not Bmp, plays important roles in root dentin formation. Moreover, exogenous TGF- $\beta 1$ can induce odontoblast differentiation and dentin formation in dental papilla cells in vitro. ${ }^{71-73}$ Following inactivation of Smad4 in dental epithelial cells (HERS) in K14-Cre;Smad4 $4^{f l / f l}$ mutant mice, the development of molar roots is arrested and the formation of dentin is also severely affected. Smad4mediated TGF- $\beta$ /BMP signaling is required in the dental epithelium for Shh expression in the HERS and Nfic expression in the CNCderived dental mesenchyme. Ectopic Shh induces Nfic expression in the dental mesenchyme and partially rescues root development in K14-Cre;Smad4 $4^{f l f l}$ mice. $^{20}$ Thus, we conclude that TGF- $\beta /$ BMP signaling in the HERS relies on a Smad4-dependent mechanism that regulates $N$ fic expression via Shh signaling in the dental papilla.

\section{Nfic}

Nfic is a member of the nuclear factor I family, which includes Nfia, Nfib, Nfic and Nfix. ${ }^{74}$ The four nuclear factor I members function independently. Nfic has a specific function as a key regulator of root dentin formation. In molars of Nfic mutant mice, the crown develops normally, but molar root development is defective due to abnormal dentin formation. ${ }^{17-18,20}$ The defective dentin in Nfic mutant mice is 
similar to that of Tgf- $\beta 1$-overexpressing transgenic mice. ${ }^{37}$ As mentioned above, Nfic is a downstream target of TGF- $\beta 1$ signaling during tooth root development. Tgf- $\beta 1$ induces odontoblast differentiation through the Smad pathway by increasing p21 and other Tgf- $\beta$ responsive gene expression levels via the degradation of Nfic, which suppresses p21 expression. During early odontoblast differentiation, Tgf- $\beta 1$ and MAPK activation enhances the formation of a Smad2/3Nfic-Smurf1/2 complex and results in the degradation of Nfic. During late odontoblast differentiation and mineralization, Nfic signaling results in the dephosphorylation of $\mathrm{p}-\mathrm{Smad} 2 / 3$. Consequently, Tgf$\beta 1$ induces odontoblast differentiation through the Smad signaling pathway in early odontoblast differentiation, whereas Nfic signaling modulates late odontoblast differentiation and mineralization. ${ }^{37}$

\section{Shh}

Shh, a member of the hedgehog signaling family, is expressed in the dental epithelium and plays an essential role during tooth development. ${ }^{15}$ During root development, Shh is strongly expressed in the HERS, which suggests a function in root formation. Patched, the membrane receptor of Shh, and Gli1, a transcript activated by Shh, are also detectable in the root epithelium (HERS) and mesenchyme. ${ }^{61-62}$ The partial rescue of root development by Shh in rootless K14-Cre;Smad $4^{\text {fl/fl }}$ mutant mice indicates the essential function of Tgf- $\beta$-mediated Shh signaling in regulating root formation. ${ }^{20}$

\section{Fgf3 and Fgf10}

Fgfs are expressed in the dental epithelium and mesenchyme during tooth crown formation. However after birth, their expression changes. For example, Fgf3 and Fgf10 are expressed in the dental mesenchyme during the bud and bell stages of tooth crown development, but after birth, their expression is dramatically reduced. In contrast, Fgf3 and Fgf10 are expressed in the dental mesenchyme and help to maintain stem cell proliferation in the cervical loop of the incisors, which continue to grow throughout life in the mouse. In molar development, however, Fgf10 is turned off prior to root development. If Fgf10 remains active in the dental papilla of the molars during root development, the HERS will be enlarged and the root will fail to form. In voles, the molar continues to grow throughout life, and Fgf10 expression is detectable in the dental pulp adjacent to the enlarged HERS. ${ }^{75-77}$ Taken together, these data suggest that Fgf10 is an important regulator for controlling the switch from crown to root formation.

\section{Wnt}

Wnt is also important for tooth crown development, but Wnt expression is barely detectable during root development. If Wnt signaling is upregulated via inhibition of Bmp signaling, dentin formation is replaced by bone formation. Therefore, Wnt may help to control cell fate decision during mineral tissue formation. ${ }^{70}$

\section{Hepatocyte growth factor}

Hepatocyte growth factor (Hgf) is one of the mediators of epithelialmesenchymal interactions in rodent tooth. Hgf receptors are expressed in the enamel epithelium of molar germs as well as in HERS cells. Hgf stimulates root development in transplanted tooth germs, proliferation of HERS cells in culture and HERS elongation in an organ-culture system. Moreover, cell proliferation in the HERS increases after treatment with Hgf. This effect is downregulated when an antibody against the Hgf receptor is added to the culture medium. Thus, Hgf signaling controls root formation via the development of the HERS. ${ }^{78}$

\section{CONCLUSION}

We have made important great progress in studies of tooth root development in the last 10 years. Development of ectodermal organs involves similar processes and, in some cases, the same genes as those used earlier in development. ${ }^{79-81}$ Like the tooth crown, tooth root development involves the interaction of the dental epithelium and the cranial neural crest-derived mesenchyme. These reciprocal interactions are mediated by a series of signals, including from Tgf- $\beta, \mathrm{Bmp}$, Wnt, Shh, Fgf and other molecules, and by the function of homebox genes, such as Nfic and Msx1/2. This review provides an overview of root development and highlights the developmental biology of the tooth root. We hope that knowledge about the cell fate of the HERS, interaction of dental epithelial and mesenchymal cells, and other molecular mechanisms during tooth root development will facilitate tooth regeneration studies in the future.

\section{ACKNOWLEDGEMENTS}

We thank Dr Julie Mayo for critical reading of the manuscript. We apologize to those colleagues whose publications were not cited due to space limitations. This study was supported by grants from the NIDCR, NIH (DE012711 and DE014078) to Yang Chai and National Natural Science Foundation of China (81170943), Beijing Natural Science Foundation (7122051) and Funding for Talents in Beijing (D) (2010D003034000012) to Xiao-Feng Huang.

1 Brown H. Hypoplasia of the dentition. Am J Orth Oral Surg 1944; 32(2): 102-103. 2 Lind V. Short root anomaly. Scand J Dent Res 1972; 80(2): 85-93.

3 Xue Y, Wang W, Mao T et al. Report of two Chinese patients suffering from CLCN7related osteopetrosis and root dysplasia. J Craniomaxillofac Surg 2011; 40(5): 416420.

4 McKee MD, Nakano Y, Masica DL et al. Enzyme replacement therapy prevents dental defects in a model of hypophosphatasia. J Dent Res 2011; 90(4): 470-476.

5 Qin H, Yang FS. Calcitonin may be a useful therapeutic agent for osteoclastogenesis syndromes involving premature eruption of the tooth. Med Hypotheses 2008; 70(5): 1048-1050.

6 Chai Y, Slavkin HC. Prospects for tooth regeneration in the 21st century: a perspective. Microsc Res Tech 2003; 60(5): 469-479.

7 Chai Y, Maxson RE Jr. Recent advances in craniofacial morphogenesis. Dev Dyn 2006; 235(9): 2353-2375.

8 Lumsden AG. Spatial organization of the epithelium and the role of neural crest cells in the initiation of the mammalian tooth germ. Development 1988; 103(Suppl): 155169.

9 Miletich I, Sharpe PT. Normal and abnormal dental development. Hum Mol Genet 2003; 12(1): 69-73.

10 Jernvall J, Thesleff I. Reiterative signaling and patterning during mammalian tooth morphogenesis. Mech Dev 2000; 92(1): 19-29.

11 Thesleff I, Sharpe PT. Signalling networks regulating dental development. Mech Dev 1997; 67(2): 111-123.

12 Huang XF, Chai Y. TGF- $\beta$ signaling and tooth development. Chin J Dent Res 2010; 13(1): 7-13.

13 Owens PD. Ultrastructure of Hertwig's epithelial root sheath during early root development in premolar teeth in dogs. Arch Oral Biol 1978; 23(2): 91-104.

14 Diekwisch TG. The developmental biology of cementum. Int J Dev Bio/2001; 45(5/6) 695-706.

15 Luan X, Ito Y, Diekwisch TG. Evolution and development of Hertwig's epithelial root sheath. Dev Dyn 2006; 235(5): 1167-1180.

16 Aberg T, Wozney J, Thesleff I. Expression patterns of bone morphogenetic proteins (Bmps) in the developing mouse tooth suggest roles in morphogenesis and cell differentiation. Dev Dyn 1997; 210(4): 383-396.

17 Steele-Perkins G, Butz KG, Lyons GE et al. Essential role for NFI-C/CTF transcriptionreplication factor in tooth root development. Mol Cell Biol 2003; 23(3): 1075-1084.

18 Park JC, Herr Y, Kim HJ et al. Nfic gene disruption inhibits differentiation of odontoblasts responsible for root formation and results in formation of short and abnormal roots in mice. J Periodontol 2007; 78(9): 1795-1802.

19 Huang X, Bringas P, Slavkin HC et al. Fate of HERS during tooth root development. Dev Biol 2009; 334(1): 22-30.

20 Huang $\mathrm{X}, \mathrm{Xu} \mathrm{X}$, Bringas $\mathrm{P}$ Jr et al. Smad4-Shh-Nfic signaling cascade-mediated epithelial-mesenchymal interaction is crucial in regulating tooth root development. $J$ Bone Miner Res 2010; 25(5): 1167-1178.

$21 \mathrm{Xu} \mathrm{L}$, Tang L, Jin $\mathrm{F}$ et al. The apical region of developing tooth root constitutes a complex and maintains the ability to generate root and periodontium-like tissues. $J$ Periodontal Res 2009; 44(2): 275-282. 
22 Kazuhisa N, Ritsuko M, Yasumitsu S et al. The development of a bioengineered organ germ method. Nat Methods 2007; 4(3): 227-230.

23 Sonoyama W, Liu Y, Fang D et al. Mesenchymal stem cell-mediated functional tooth regeneration in swine. PLOS ONE 2006; 1 : e79.

24 Brockes JP, Kumar A. Appendage regeneration in adult vertebrates and implications for regenerative medicine. Science 2005; 310(5756): 1919-1923.

25 Atala A. Tissue engineering, stem cells and cloning: current concepts and changing trends. Expert Opin Biol Ther 2005; 5(7): 879-892.

26 Slavkin HC, Bavetta LA. Odontogenic epithelial-mesenchymal interactions in vitro. $J$ Dent Res 1968; 47(5): 779-785.

27 Huang XF, Zhao YB, Zhang FM et al. Comparative of gene expression between orthodontic tooth movement and tooth eruption. Oral Dis 2009; 15(8): 573-579.

28 Zeichner-David M. Regeneration of periodontal tissues: cementogenesis revisited. Periodontol 2000 2006; 41: 196-217.

29 Fang J, Tang L, Liu XH et al. Changes of the unique odontogenic properties of rat apical bud cells under the developing apical complex microenvironment. Int J Oral Sci2009, 1(1): 26-33.

30 Tenorio D, Cruchley A, Hughes FJ. Immunocytochemical investigation of the rat cementoblast phenotype. J Periodontal Res 1993; 28 (6 Pt 1): 411-419.

31 Ten Cate AR. A fine structural study of coronal and root dentinogenesis in the mouse. Observations of the so called von Korff fibers and their contribution to mantle dentine. J Anat 1978; 125(1): 183-197.

32 Mullen LM, Richards DW, Quaranta V. Evidence that laminin- 5 is a component of the tooth surface internal basal lamina, supporting epithelial cell adhesion. $J$ Periodontal Res 1999; 34(1): 16-24.

33 Bègue-Kirn $\mathrm{C}$, Smith $\mathrm{A}$, Loriot $\mathrm{M}$ et al. Comparative analysis of TGF betas, BMPs, IGF1, msxs, fibronectin, osteonectin and bone sialoprotein gene expression during normal and in vitro-induced odontoblast differentiation. Int J Dev Biol 1994; 38(3): 405-420.

34 Ruch J, Lesot H, Bègue-Kirn C. Odontoblast differentiation. Int J Dev Biol 1995; 39(1): 51-68.

35 Unterbrink A, O'Sullivan M, Chen S et al. TGF beta-1 downregulates DMP-1 and DSPP in odontoblasts. Connect Tissue Res 2002; 43(2/3): 354-358.

36 Oka S, Oka K, Xu X et al. Cell autonomous requirement for TGF-beta signaling during odontoblast differentiation and dentin matrix formation. Mech Dev 2007; 124(6): 409-415.

37 Lee DS, Park JT, Kim HM et al. Nuclear factor I-C is essential for odontogenic cell proliferation and odontoblast differentiation during tooth root development. J Bio Chem 2009; 284(25): 17293-17303.

38 Orban B. The epithelial network in the periodontal membrane. J Am Dent Assoc 1952; 44(6): 632-635.

39 Slavkin HC, Bringas P, Bessem C et al. Hertwig's epithelial root sheath differentiation and initial cementum and bone formation during long-term organ culture of mouse mandibular first molars using serumless, chemically-defined medium. J Periodontal Res 1988; 23(1): 28-40.

40 Thomas HF. Root formation. Int J Dev Biol 1995; 39(1): 231-237.

41 BarKana I, Narayanan AS, Grosskop A et al. Cementum attachment protein enriches putative cementoblastic populations on root surfaces in vitro. J Dent Res 2000; 79(7) $1482-1488$.

42 McAllister B, Narayanan AS, Miki Y et al. Isolation of a fibroblast attachment protein from cementum. J Periodontal Res 1990; 25(1): 99-105.

43 Palmer RM, Lumsden AG. Development of periodontal ligament and alveolar bone in homografted recombination's of enamel organs and papillary, pulpal, and follicular mesenchyme in the mouse. Arch Oral Biol 1987; 32(4): 281-289.

$44 \mathrm{Yu}$ J, McMahon AP, Valerius MT. Recent genetic studies of mouse kidney development. Curr Opin Genet Dev 2004; 14(5): 550-557.

45 del Moral PM, Warburton D. Explant culture of mouse embryonic whole lung, isolated epithelium, or mesenchyme under chemically defined conditions as a system to evaluate the molecular mechanism of branching morphogenesis and cellular differentiation. Methods Mol Biol 2010; 633: 71-79.

46 Kobayashi H, Kromminga A, Dunlop TW et al. A role of melatonin in neuroectodermalmesodermal interactions: the hair follicle synthesizes melatonin and expresses functional melatonin receptors. FASEB J 2005; 19(12): 1710-1712.

47 Yang TL, Hsiao YC, Lin SJ et al. Biomaterial mediated epithelial-mesenchymal interaction of salivary tissue under serum free condition. Biomaterials 2010; 31(2): 288-295.

48 Zhao Z, Rivkees SA. Tissue-specific expression of GTPas RalA and RalB during embryogenesis and regulation by epithelial-mesenchymal interaction. Mech Dev 2000; 97(1/2): 201-204.

49 Chabanski MB, Gillam DG, Bulman JS et al. Prevalence of cervical dentine sensitivity in a population of patients referred to a specialist Periodontology Department. J Clin Periodontol 1996; 23(11): 989-992.

50 Shimazu Y, Sato K, Aoyagi K et al. Hertwig's epithelial cells and multi-root development of molars in mice. J Oral Biosci 2009; 51(4): 210-221.

51 Cerri PS, Katchburian E. Apoptosis in the epithelial cells of the rests of Malassez of the periodontium of rat molars. J Periodontal Res 2005; 40(5): 365-372.

52 Cerri PS, Freymuller E, Katchburian E. Apoptosis in the early developing periodontium of rat molars. Anat Rec 2000; 258(2): 136-144.
53 Kaneko $\mathrm{H}$, Hashimoto S, Enokiya $\mathrm{Y}$ et al. Cell proliferation and death of Hertwig's epithelial root sheath in the rat. Cell Tissue Res 1999; 298(1): 95-103.

54 Wentz FM, Weinmann JP, Schour I. The prevalence, distribution, and morphologic changes of the epithelial remnants in the molar region of the rat. J Dent Res 1950; 29(2): 637-646

55 Sonoyama W, Seo BM, Yamaza T et al. Human Hertwig's epithelial root sheath cells play crucial roles in cementum formation. J Dent Res 2007; 86(7): 594-599.

56 Zeichner-David M, Oishi K, Su Z et al. Role of Hertwig's epithelial root sheath cells in tooth root development. Dev Dyn 2003; 228(4): 651-663.

57 Andujar MB, Maglorie H, Hartmann DJ et al. Early mouse molar root development: cellular changes and distribution of fibronectin, laminin and type-IV collagen. Differentiation 1985; 30(2): 111-122.

58 Yamashiro T, Tummers M, Thesleff I. Expression of bone morphogenetic proteins and Msx genes during root formation. J Dent Res 2003; 82(3): 172-176.

59 Yamashiro T, Tummers M, Thesleff I. Modulation of epithelial cell fate of the root in vitro. J Dent Res 2007; 86(11): 1063-1067.

60 Hammerschmidt M, Brook A, McMahon AP. The world according to hedgehog. Trends Genet 1997; 13(1): 14-21.

61 Dassule HR, Lewis $\mathrm{P}$, Bei $\mathrm{M}$ et al. Sonic hedgehog regulates growth and morphogenesis of the tooth. Development 2000; 127(22): 4775-4785.

62 Koyama E, Wu CS, Shimo T et al. Development of stratum intermedium and its role as a Sonic hedgehog-signaling structure during odontogenesis. Dev Dyn 2001; 222(2): 178-191.

63 Nakao A, Kajiya H, Fukushima $\mathrm{H}$ et al. PTHrP induces Notch signaling in periodontal ligament cells. J Dent Res 2009; 88(6): 551-556.

64 Massague J. How cells read TGF-b signals. Nat Rev Mol Cell Biol 2000; 1(3): 169 178.

65 Siegel PM, Massagué J. Cytostatic and apoptotic actions of TGF-beta in homeostasis and cancer. Nat Rev Cancer 2003; 3(11): 807-821.

66 Massagué J, Weis-Garcia F. Serine/threonine kinase receptors: mediators of transforming growth factor beta family signals. Cancer Surv 1996; 27: 41-64.

67 Lagna G, Hata A, Hemmati-Brivanlou A et al. Partnership between DPC4 and Smad proteins in TGF- $\beta$ signaling pathways. Nature 1996; 383(6603): 832-836.

$68 \mathrm{Wu} \mathrm{R}$, Zhang $\mathrm{Y}$, Feng $\mathrm{X}$ et al. Heteromeric and homomeric interactions correlate with signaling activity and functional cooperativity of Smad3 and Smad4 (DPC4). Mol Cell Biol 1997; 17(5): 2521-2528.

69 Derynck R, Zhang YE. Smad-dependent and Smad-independent pathways in TGF- $\beta$ family signalling. Nature 2003; 425(6958): 577-584.

70 Li JY, Huang XF, Xu X et al. Smad4-mediated WNT signaling controls the fate of cranial neural crest cells during tooth morphogenesis. Development 2011; 138(10): 19771989.

71 Smith AJ, Matthews JB, Hall RC. Transforming growth factor-betal (TGF-beta1) in dentine matrix. Ligand activation and receptor expression. Eur J Oral Sci 1998; 106(Suppl 1): 179-184.

72 Hwang YC, Hwang IN, Oh WM et al. Influence of TGF-betal on the expression of BSP, DSP, TGF-beta 1 receptor I and Smad proteins during reparative dentinogenesis. $J \mathrm{Mol}$ Histol 2008; 39(2): 153-160.

73 Thyagarajan T, Sreenath T, Cho A et al. Reduced expression of dentin sialophosphoprotein is associated with dysplastic dentin in mice overexpressing transforming growth factor- $\beta 1$ in teeth. J Biol Chem 2001; 276(14): 11016-11020.

74 Gronostajski RM. Role of NFI/CTF gene family in transcription and development. Gene 2000; 249(1/2): 31-45.

75 Yokohama TT, Ohshima H, Fujiwara $\mathrm{N}$ et al. Cessation of Fgf 10 signaling, resulting in a defective dental epithelial stem cell compartment, leads to the transition from crown to root formation. Development 2006; 133(7): 1359-1366.

76 Madan AK, Kramer B. Immunolocalization of fibroblast growth factor-2 (FGF-2) in the developing root and supporting structures of the murine tooth. J Mol Histol 2005; 36(3): 171-178.

77 Harada H, Toyono $\mathrm{T}$, Toyoshima K et al. FGF10 maintains stem cell compartment in developing mouse incisors. Development 2002; 129(6): 1533-1541.

78 Sakuraba H, Fujiwara N, Sasaki-Oikawa A et al. Hepatocyte growth factor stimulates root growth during the development of mouse molar teeth. J Periodontal Res 2012; 47(1): 81-88.

79 Thesleff I, Sharpe PT. Signalling networks regulating dental development. Mech Dev 1997; 67(2): 111-123.

80 Mikkola ML, Millar SE. The mammary bud as a skin appendage: unique and shared aspects of development. J Mam Gland Biol Neoplasia 2006; 11(3/4): 187-203.

81 Fuchs E. Scratching the surface of skin development. Nature 2007; 22(7130): 834 842 .

\section{(c)}

This work is licensed under a Creative Commons Attribution-NonCommercial-NoDerivative Works 3.0 Unported License. To view a copy of this license, visit http:// creativecommons.org/licenses/by-nc-nd/3.0 